\title{
História intelectual e projetos políticos nas propostas de hispanismo de António Sardinha, Angel Ganivet e Miguel de Unamuno
}

Felipe Cazetta ${ }^{1 *}$

\section{RESUMO}

Através da história transnacional, porém com maior ênfase à história intelectual, busca-se examinar a relação de coesão e tensão apresentada por escritores como Unamuno e Ganivet, na Espanha, e António Sardinha, em Portugal. Embora os intelectuais destacados apresentassem projetos congêneres de aproximação das relaçôes diplomáticas entre os países ibéricos e destes com os latino-americanos, cada qual mantinha suas especificidades, e por vezes mantiveram diferenças entre os projetos políticos, quando postos em debate. Assim, o artigo tem como proposta a apresentação do contexto de produção dos textos, tal como a análise da produçáo política desses autores destacados.

Palavras-chaves: intelectuais; política; hispanismo.

\section{Intellectual History and Political Projects in the Proposals of Hispanism of António Sardinha, Angel Ganivet and Miguel de Unamuno}

\begin{abstract}
Through transnational history, but with a greater emphasis on intellectual history, the aim of the article is to present the relationship of cohesion and tension presented by writers such as Unamuno and Ganivet in Spain, and António Sardinha in Portugal. Even though the aforementioned intellectuals had similar projects of making the diplomatic relations between the Iberian countries themselves closer, as well as their relations with Latin American countries, they maintained their specificities, and sometimes they maintained differences between the political projects when those were debated. Thus, the article proposes the presentation of the context of production of the texts, such as the analysis of the political production of these outstanding authors.
\end{abstract}

Keywords: intellectuals; politics; Hispanism.

DOI: http://dx.doi.org/10.1590/2237-101X01903807

Artigo recebido em 30 de junho de 2017 e aprovado para a publicaçáo em 17 de outubro de 2017.

${ }^{1}$ Universidade Estadual de Montes Claros, Montes Claros, Minas Gerais, Brasil.

* Professor da Universidade Estadual de Montes Claros. E-mail: felipecazetta@yahoo.com.br. 


\section{Historia intelectual y proyectos políticos en las propuestas de hispanismo de António Sardinha, Angel Ganivet y Miguel de Unamuno}

\section{RESUMEN}

A través de la historia transnacional, pero con mayor énfasis en la historia intelectual, se busca examinar la relación de cohesión y tensión mostrada por escritores tales como Unamuno y Ganivet, en España, y António Sardinha, en Portugal. A pesar de que los intelectuales destacados tuviesen proyectos congéneres de aproximación de las relaciones diplomáticas entre los países ibéricos y de éstos con los latinoamericanos, cada uno mantenía sus especificidades, y en ocasiones sustentaron diferencias entre los proyectos políticos, cuando puestos en debate. De esta forma, el artículo tiene como propuesta la presentación del contexto de producción de los textos, tal como el análisis de la producción política de estos autores destacados.

Palabras clave: intelectuales; políticos; hispanismo.

Intelectuais e política como aplicação metodológica: o Estado da Arte sobre o hispanismo e os estudos acerca do "Desastre"

António Sardinha, Angel Ganivet e Miguel de Unamuno foram intelectuais ibéricos, o primeiro português e os demais, espanhóis, defensores de projetos políticos e, portanto, dotados de engajamento. Antes de analisar a trajetória, as redes e os espaços de sociabilidade, tal como as sustentações das propostas políticas, creio ser importante estabelecer algumas noçóes sobre o próprio conceito de intelectual, e de história intelectual trabalhados a seguir, para que os personagens históricos apresentados sejam melhor delineados e inseridos em seus devidos espaços de atuação.

Assim, podemos dizer que o intelectual enquanto objeto de pesquisas acadêmicas foi revitalizado nos anos 1980. Anteriormente, o distanciamento entre os estudos e as análises com o objeto se justificou em função da hegemonia desfrutada pela Escola dos Annales. A ênfase dada à história serial, desenvolvida pela terceira geração, fez dos “intelectuais” alvo desinteressante de estudos para os historiadores dos Annales. Quando abordados como objetos de pesquisa, os círculos intelectuais demonstravam-se arredios aos levantamentos quantitativos ou de inserirem-se na média ou longa duração, temporalidades eleitas pelos Annales, já em sua segunda geração, como ideais às pesquisas históricas. Outro impedimento, consonante aos anteriores, se mantinha pelo universo intelectual ser visto como restrito à curta duração.

Deste modo, o intelectual foi colocado no ostracismo das pesquisas acadêmicas entre os anos 1960 e 1970 por um importante segmento historiográfico. ${ }^{2}$ Tal como apontado por François Dosse, "a história intelectual era considerada como muito próxima ao individual,

\footnotetext{
${ }^{2}$ SILVA, Helenice Rodrigues da. Fragmentos da história intelectual: entre questionamentos e perspectivas. Campinas, SP: Papirus, 2002, p. 37.
} 
à biografia e ao político, objetos desvalorizados pela história erudita". ${ }^{3} \mathrm{O}$ empenho em dignificar a política como componente do universo possível de ser investigado, executado por historiadores que se colocavam à margem dos Annales, tomou relevo na década de $1980 \mathrm{e}$ ressaltou a potencialidade das análises do comportamento coletivo, por meio dos votos, dos manifestos, dos abaixo-assinados e dos movimentos sociais.

Os métodos inaugurados por Sirinelli, Berstein e Remond ${ }^{4}$ incorporaram na política abordagens culturais e provenientes das mentalidades. Nesse esforço, os grupos intelectuais, como objeto de pesquisa, foram favorecidos, em vista da articulação mantida entre história política e intelectual. Em outras palavras, foram revistos ou redefinidos o prestígio do individual sobre o coletivo, a prioridade do evento sobre a regularidade, e a impossibilidade ou dificuldade de se realizar análises seriais, quantitativas, em vista do número reduzido de componentes, e esses métodos passaram a ter aplicação na história política e intelectual.

De fato, a história intelectual está associada à história política, conforme defendido por Sirinelli. Entendida como abordagem global de comportamentos individuais, o historiador francês apresenta a história intelectual, inserida em sua função política, como campo privilegiado para se analisar ideologias, culturas políticas e valores inerentes a grupos, espaços de sociabilidade e geraçóes. ${ }^{5} \mathrm{Na}$ mesma via, a mudança de escala do global para o singular, mantida pelos pesquisadores das áreas de ciências humanas e sociais, recuperou o interesse na política e no universo intelectual como destinos de pesquisa e desenvolvimento de exames.

O indivíduo, visto como portador de projetos e valores, foi dotado de interesses pelo mundo acadêmico, e assim destacada sua capacidade de estabelecer redes, estratégias e engajamento. $\mathrm{O}$ rastreamento das trajetórias ${ }^{6}$ individuais conduzia a novas conclusôes sobre organização do grupo, hierarquias e disputas internas no fomento de concepçôes e projetos que se organizariam como identidade política e legitimidade de práticas, institucionais ou não, de organizaçôes, movimentos, grupos e partidos dos quais não é possível afastar a atuação do intelectual.

Uma vez reabilitada ao campo de pesquisa acadêmica, percebe-se a polissemia que circunscreve as definiçôes da história intelectual. Jean-François Sirinelli defende que os conceitos sofrem mutaçôes conforme as mudanças na sociedade, e para o caso dos intelectuais não foi diferente em referência ao contexto francês. Assim, destaca duas definiçôes, sendo “(...) uma ampla e sociocultural, englobando os criadores e 'mediadores' culturais, e outra mais estreita, baseada na noção

\footnotetext{
3 "Entonces la historia intelectual era considerada como demasiado próxima a lo individual, a lo biográfico y a lo politico, objeto todos ellos, devaluados por la historia erudita" (tradução livre). DOSSE, François. La marcha de las ideas: historia de los intelectuales, historia intelectual. València: Universitat de València, 2007, p. 12.

${ }^{4}$ REMOND, René (Org.). Por uma história politica. Rio de Janeiro: Editora UFRJ/Fundação Getulio Vargas, 1996.

${ }_{5}^{5}$ SIRINELLI, Jean-François. Intellectuels et passions françaises: manifestes et petitions au XX siècle. Paris: Librairie Arthème Fayard, 1990, p. 16-17.

${ }^{6}$ SILVA, Helenice Rodrigues da. Fragmentos da história intelectual: entre questionamentos e perspectivas, op. cit., p. 51.
} 
de engajamento". Unamuno e Ganivet, na Espanha; e Sardinha, em Portugal, inserem-se na segunda categoria apontada sobre a definição de "intelectual”. Havia entre os autores destacados a preocupação em revitalizar os aportes culturais de seus respectivos países, para fora de suas fronteiras, diante da ameaça imperialista oferecida pelos países anglo-saxóes e pela França.

Em El porvenir de España, Unamuno debateu com Ganivet sobre os projetos políticos domésticos e internacionais para recuperar o lugar perdido pela Espanha após as derrotas em guerras para os Estados Unidos no final do século XIX, que culminaram na independência ou na anexação de Cuba, de Porto Rico e das Filipinas pelo país vitorioso: "Mais de uma vez se disse que o espanhol tratou de elevar o índio a si, e isto não é, no fundo, mais que uma imposição de soberania. O único modo de elevar o próximo é ajudá-lo a ser mais a si, a que se depure sua própria linha, e não na nossa." ${ }^{8}$ Logo, procuraram elaborar projetos de relaçóes internacionais que destacassem a soberania nacional, sem, no entanto, afetar a do país que se propunha diálogo. Havia o interesse em reaproximarem-se das antigas colônias, porém, alterando a relação de metrópole, mantida pela Espanha.

Desse modo, o engajamento era evidente nesses textos, por demonstrarem preocupaçáo em relação aos percursos nacionais. A investida cultural é sobressaltada no caso de António Sardinha e seu grupo integralista lusitano, em vista da negação inicial da política institucional, entendida por eles como corrompida pelo liberalismo. Assim, o polo de agregação e sociabilidade se fazia, inicialmente, por meio da partilha de gostos e da erudição literária. Portanto, comportavam correntes políticas distintas, que posteriormente foram se afunilando no monarquismo corporativo. Logo a relação da "cultura" enquanto forma de engajamento, no caso português se fazia da seguinte maneira:

Os fundadores do Integralismo Lusitano, na sua maior parte, antigos companheiros da Universidade de Coimbra, que uma camaradagem unira estreitamente. Não que houvesse afinidades políticas entre eles: uns eram monárquicos, outros republicanos ou indiferentes e outros que ainda não tinham concluído. O que os ligava eram afinidades literárias e estéticas, era uma comum preocupação cultural, era a superioridade da inteligência que os ligava e os levava a afastar-se desdenhosamente das truculências demagógicas e das paixóes acadêmicas de então.?

Dito isso, percebe-se que, entre os finais do século XIX e início do XX, grupos de artistas, escritores, acadêmicos e pensadores de modo geral passam a inclinar-se, cada círculo ao seu

\footnotetext{
${ }^{7}$ SIRINELLI, Jean-François. Os intelectuais . In: REMOND, Renè (Org.). Por uma história política. Rio de Janeiro: Editora da UFRJ/FGV, 1996, p. 242.

8 "Mas de una vez ha dicho que el español trató de elevar al indio a si, y esto no es en el fondo mas que una imposición de soberanía. El único modo de elevar el prójimo es ayudarle á que sea más el cada vez, á que depure su linea propia, no en la nuestra." UNAMUNO, Miguel de; GANIVET, Angel. El porvenir de España. Madri: Renacimiento Sociedad Anonima Editorial, 1912 p. 35 (tradução livre, grifo do original). ${ }^{9}$ ASCENSÃO, Leão Ramos. O Integralismo Lusitano. Lisboa: Ediçóes Gama, 1943 p. 10.
} 
modo, sobre problemas de cunho nacional. Esse engajamento acabaria por desembocar em preocupaçóes políticas, que por vezes resultavam na elaboração de projetos e propostas de saída da crise e reorganização do poder. Assim, através de suas concepçóes e influenciados por seus respectivos espaços de sociabilidade, sustentaram propostas heterogêneas em seus formatos e suas aplicações.

Tais estratégias e projetos para reabilitar seus respectivos países não passaram despercebidos pelos pesquisadores, principalmente nas últimas duas décadas. Entre os investigadores portugueses e brasileiros houve a percepção da polifonia envolvida na proposta de hispanidade, resultante do momento declínio e pessimismo que acometeu os pensadores na Península Ibérica da virada dos anos 1890 e $1900 .^{10}$

Munida da proposta de transnacionalidade, Susana Relvas examina em suas pesquisas ${ }^{11}$ a capacidade de Sardinha em circular entre a fronteira de Espanha e Portugal. Desse modo, a pesquisadora sublinha os espaços de sociabilidade e as influências apropriadas pelo mentor do Integralismo Lusitano, entre as quais a da "Geração de 1898", no intuito de compreender as bases da proposta de Hispanidade lançadas pelo integralista. Em mesma via, Paulo Ferreira ${ }^{12}$ estabelece apropriações, circulações e funcionalidades inseridas nos projetos políticos, representados pelas definições de iberismo e hispanidade.

Cristina Gouveia ${ }^{13}$ volta suas análises, especificamente, para o "Desastre" espanhol e o impacto que repercutiu entre os intelectuais da chamada "Geração de 1898" diante da necessidade de reorganizar o quadro hegemônico espanhol, em contexto de avanço imperialista, com destaque às potências anglo-saxãs, sobre as ex-colônias hispânicas. Em sentido semelhante, Maria Helena Capelato ${ }^{14}$ discorre sobre os impactos políticos no quadro intelectual espanhol. A partir desse panorama historiográfico, percebe-se a importância que os estudos transnacionais, nesse caso, com ênfase à intelectualidade da Península Ibérica na virada do século XIX para XX, desfrutam em investigaçôes dos anos 2000 até o momento. É a partir desses percursos que este artigo irá se respaldar, com auxílio da história intelectual.

\footnotetext{
${ }^{10}$ Com o levantamento bibliográfico a seguir, não há a pretensão de esgotar a literatura sobre o assunto, mas tão somente apontar os referenciais utilizados nesta pesquisa.

${ }^{11}$ RELVAS, Susana Soares de Silva Rocha. António Sardinha e suas relaçóes culturais com a Espanha: "Pactos de Quinas y Flores de Lis" entre "os semeadores de Nacionalidade". Dissertação (Mestrado em Literatura Comparada Portuguesa e Espanhola) - Departamento de Línguas e Literaturas Românicas, Faculdade de Ciências Sociais e Humanas da Universidade Nova de Lisboa, Lisboa, 1998. Biblioteca Nacional de Lisboa. Cota: L.62184V.

${ }^{12}$ FERREIRA, Paulo Bruno Rodrigues. Iberismo, hispanismo e seus contrários: Portugal e Espanha (19081931). Tese (Doutorado em História) — Universidade de Lisboa, Lisboa, 2016.

${ }^{13}$ GOUVEIA, Regiane Cristina. A "Geração de 1898", o "Desastre" e a retomada das relaçôes entre Espanha e as repúblicas hispano-americanas. In: Simpósio Nacional de História - ANPUH, jul. 2011, São Paulo. Anais do XXVI Simpósio Nacional de História - ANPUH, São Paulo, julho de 2011.

${ }^{14}$ CAPELATO, Maria Helena Rolim. A data símbolo de 1898: o impacto da independência de Cuba na Espanha e na Hispanoamérica. História, São Paulo, v. 22, n. 2, p. 35-58, 2003.
} 
Revistas, livros, correspondências, manifestos, textos escritos, de modo geral, constituem um dos suportes essenciais para o campo intelectual, ${ }^{15}$ em que são utilizadas como plataforma política, ferramenta de divulgação teórica, área de contato e intercâmbio com seus pares. Por meio dos periódicos, assim como das demais publicaçôes, é possível estabelecer o itinerário, as relações geracionais e os interlocutores dos intelectuais, componentes das redes estabelecidas por eles. ${ }^{16}$ A partir dessas ferramentas de expressão de suas convicçôes, ideologias, teorias e projetos políticos, os intelectuais, voluntária ou involuntariamente, saem de suas regióes de conforto, ou seja, o domínio de sua competência erudita, para serem conhecidos pela comunidade exterior aos círculos acadêmicos ou de partilha cotidiana de pensamentos e formulação de visóes de mundo. Desse modo, ficam, em certa medida, acusados os tipos de fontes a serem trabalhadas ao longo do artigo. Em outros termos, livros e periódicos foram o espaço destacado para se examinar o debate e as disputas sobre a autoridade conceitual e, portanto, do próprio projeto político da hispanidade, e das propostas de alianças peninsulares inscritas em seus textos.

Da necessidade de contribuírem com a recuperação de seus países, esses personagens saem do estatuto de meros pensadores acadêmicos para migrarem para as esferas nacionais de política. Para Dosse, é esse comprometimento com questôes que fogem do escopo catedrático ou erudito que compôe a definiçáo do intelectual contemporâneo. ${ }^{17}$ Salvo melhor juízo, esse comportamento encontra como marco fundador para o engajamento político social dos intelectuais o final do século XIX, com o Caso Dreyfus.

Esse capítulo da história francesa consistiu no julgamento do oficial militar judeu Alfred Dreyfus, pela acusação de traição à nação por vender segredos militares à Alemanha. Uma vez condenado ao degredo, professores universitários, bacharéis, jornalistas e escritores empenharam-se por demonstrar as inconsistências dentro do processo. Tal engajamento levou à denominação pejorativa e irônica de "intelectuais", por Maurice Barrès, futuro membro da Ação Francesa - movimento de extrema direita de forte investimento à monarquia corporativa e ao nacionalismo exacerbado. Portanto, como desdobramento do Caso Dreyfus houve a polarização do debate na arena de disputa pela defesa da nação por parte dos anti-Dreyfus, e em nome dos Direitos Universais do Homem como denominador dos dreyfusards. ${ }^{18}$

Os setores contrários ao capitão acusado repudiaram a posição do grupo empenhado na defesa de Dreyfus, por condenarem a interferência destes no debate público, identificando-os como traidores do "instinto vital da nação". ${ }^{19}$ Tais debates entre a participação ou a repreensão da atuação nos debates cívicos levou à divisão política do meio intelectual, a partir

\footnotetext{
${ }^{15}$ DOSSE, François. La marcha de las ideas: historia de los intelectuales, historia intelectual, op. cit., p. 51.

${ }^{16}$ SIRINELLI, Jean-François. Intellectuels et passions françaises: manifestes et petitions au XX siecle. Paris Librairie Arthème Fayard, 1990, p. 19.

${ }^{17}$ DOSSE, François. La marcha de las ideas: historia de los intelectuales, historia intelectual, op. cit., p. 66-67.

${ }^{18}$ WINOCK, Michel. O século dos intelectuais. Rio de Janeiro: Bertrand Brasil, 2000, p. 45.

${ }^{19}$ Ibidem, p. 33-34.
} 
do desdobramento dos Direitos Humanos, defendida por intelectuais como Émile Zola; e, como reação, a Liga da Pátria Francesa, ainda que efêmera, de forte caráter autoritário e polo de coesão para a formação posterior de grupos como a Ação Francesa, chefiada por Charles Maurras.

Embora Helenice Rodrigues da Silva entenda os dreyfusards como intelectuais de esquerda que usufruíam de certa notoriedade ${ }^{20}$ é precoce estabelecer delineamento ideológico a partir do Caso Dreyfus. A divisão se manifestou com maior evidência entre os defensores da pátria a todo custo e os empenhados no julgamento íntegro, sem considerar os espectros ideológicos de direita e esquerda, em um primeiro momento. Winock apresenta alguns nomes presentes na lista de apoio a Dreyfus, ${ }^{21}$ e nesta, se por um lado havia a presença de Émile Zola, engajado nas pautas reconhecidamente de esquerda em suas obras, percebe-se também a participação de Georges Sorel, que no período defendia o sindicalismo revolucionário, porém no início do século XX declarou sua simpatia à Ação Francesa; e Émile Durkheim, um dos pais das ciências sociais, que se acomoda com dificuldade entre as concepçóes tradicionalmente de esquerda. Desse modo, percebe-se a necessidade de estabelecer a trajetória dos indivíduos entre os espaços de sociabilidade intelectual, diante da complexidade e da permeabilidade que esses atores desfrutam, em termos políticos e ideológicos.

De outro modo, o Caso Dreyfus inspirou, de fato, movimentos de extrema-direita. Afinal, foi nesse ocorrido que Charles Maurras se lançou como representante do conservadorismo autoritário e nacionalista. Sob as bases de monarquismo corporativo, descentralizado em termos administrativos, mas concentrado politicamente, a Ação Francesa forneceu bases para movimentos congêneres que extrapolavam as fronteiras francesas, conforme foi o caso do Integralismo Lusitano, e inspirou outros intelectuais, tal foi o caso de António Sardinha.

Diante dessas bases conceituais e metodológicas, o artigo se propõe a investigar António Sardinha, Angel Ganivet e Miguel de Unamuno como intelectuais que se lançaram às propostas políticas. Diante dessa meta o uso do hispanismo, como categoria de resgate nacional, para os intelectuais a serem analisados, aponta as respectivas saídas para o momento conturbado passado por Portugal e pela Espanha. Por outro lado, se busca perceber a heterogeneidade e a especificidade do pensamento e, consequentemente, dos projetos políticos, sustentados por esses intelectuais, ainda que dialogassem, por vezes, com as mesmas matrizes e correntes ideológicas.

\footnotetext{
${ }^{20}$ SILVA, Helenice Rodrigues da. Fragmentos da história intelectual: entre questionamentos e perspectivas, op. cit., p. 15.

${ }^{21}$ WINOCK, Michel. O século dos intelectuais, op. cit., p. 32.
} 


\section{António Sardinha: mentor do Integralismo Lusitano e polo de simpatia ao hispanismo}

Conforme já exposto, os intelectuais agrupam-se e definem-se a partir de um espaço de sociabilidade, de círculos de debates, revistas, entre outras formas de estreitar vínculos de identidade. O Integralismo Lusitano, por sua vez, foi composto por estudantes da Universidade de Coimbra que, embora detentores de situação financeira acima da média acadêmica, definiam-se pelo elitismo intelectual, e não econômico. ${ }^{22}$ Tal posição aristocrática fez que o grupo de colegas interpretasse os assuntos políticos de forma negativa. Conforme dito, foi na literatura que o círculo de sociabilidade encontrou solidez.

Em Ao ritmo da ampulheta, obra póstuma publicada em 1925, António Sardinha teceu relação entre a origem da Action Française e a do grupo do qual se destacou como principal mentor. Ao recordar um trecho de Quand les Français ne saimaient pas, ${ }^{23}$ de Charles Maurras, Sardinha observava que a formação do movimento francês estava na literatura, sendo esta a responsável por conduzir o movimento de Maurras aos assuntos políticos. Nesse sentido, António Sardinha acrescentou: "Ao pensar um pouco nas nossas origens literárias — nas de Hipólito Raposo e nas minhas, eu reconheço que também a nós as Letras nos conduziram à Política." ${ }^{24} \mathrm{~A}$ indiferença inicial com assuntos políticos implicou heterogeneidade de itinerários durante a proclamação da república portuguesa, em 1910.

Se alguns colegas não adotaram qualquer medida de reprovação ao novo regime, diante de suas coloraçôes políticas republicanas, outros se engajaram no intuito golpista, motivados pela instauração da monarquia. Sardinha expressava seu entusiasmo pela República, em detrimento da coroa deposta, nas seguintes palavras, em carta para sua noiva: "Oh! Minha amiga, como te escrevo a tremer possuído da agitação sagrada que faz os heróis, e sem qual nada de glorioso no mundo consegue. Triunfará a Revolução? Andará ela na rua a emancipar-nos a preparar a sementeira de luz de que amanhã surgir Portugal Novo?" ${ }^{25}$ Por outro lado, colegas envolvidos em sediçóes antirrepublicanas foram degredados. Entre eles estavam:

(...) Domingos Gusmão Araújo, Luis de Almeida Braga, Rolão Preto e outros rapazes emigrados em Gand, para onde arrastou o desastre da segunda incursão da Galiza, fundavam a revista Alma Portuguesa, de efêmera duraçáo, em que pela primeira vez aparece concretamente formulado, embora num sentido puramente literário, o nacionalismo português. ${ }^{26}$

\footnotetext{
${ }^{22}$ PINTO, António Costa. Os Camisas Azuis: ideologia, elites e movimentos fascistas em Portugal - 19141945. Lisboa: Editorial Estampa, 1994, p. 26.

${ }^{23}$ MAURRAS, Charles. Quand les Français ne saaimaient pas: chronique d'une Renaissance - 1895-1905. 2. ed. Paris: Nouvelle Librarie Nationalle, 1916.

${ }^{24}$ SARDINHA, António. Ao ritmo da ampulheta. Lisboa: Qp, 1978, p. 149.

${ }^{25}$ VRBATA, Ales Tenório Luna. La philosophie maurrasianne et les modalités du fascisme au Portugal. Kias Paper, p. 21-57, 2006. (Cabinet of Ibero-american Studies: Faculty of Humanities: University Hradec Králové). p. 31.

${ }^{26}$ RAPOSO, Hipólito. Dois nacionalismos: L’Action Française e o Integralismo Lusitano. Lisboa: Livraria Ferrin, 1929, p. 37.
} 
Tal revista teve apenas dois números, lançados em maio e em setembro de 1913, porém, foi o primeiro esforço de organização teórica do grupo, sob o formato de movimento. Melhor sorte foi a da revista Nação Portuguesa, fundada por Sardinha, convertido ao ideal monarquista diante da rápida desilusão com a experiência republicana, juntamente Hipólito Raposo e Alberto Monsaraz, já defensores da causa real. Esse periódico foi um dos principais órgãos de divulgação do pensamento político do integralista lusitano, ou seja, a condenaçáo de qualquer fórmula liberal constitucionalista, fosse ela republicana ou monarquista. Defendiam o rei detentor de poderes concentrados politicamente e descentralizados administrativamente, em outras palavras, a monarquia orgânica, projeto de forte inspiração na Ação Francesa, de Charles Maurras.

$\mathrm{O}$ encerramento do período de degredo náo significou arrefecimento dos projetos de instauração da monarquia orgânica em detrimento da democracia liberal e do regime republicano. Em 1915 foi realizado o ciclo de Conferências na Liga Naval. ${ }^{27}$ Neste foi tratada a Questão Ibérica em debates sobre os riscos a que Portugal estava submetido, em vista do imperialismo espanhol. Apesar de haver distinçôes sobre os assuntos e áreas exploradas, as conclusôes caminharam para o alerta da possível anexação de Portugal pela Espanha, diante do suposto poderio do país vizinho, que manteve sua coroa.

Os palestrantes foram: António Sardinha ("Território e Raça", em 7 de abril de 1915); Hipólito Raposo ("A Língua e a Arte", em 21 de abril de 1915); Luis de Freitas Branco ("Música e Instrumentos", em 5 de maio de 1915); José Pequito Rebello ("Aspectos Econômicos"); Ruy Ennes Ulrich ("Colonizaçôes Ibéricas"); Vasco de Carvalho ("Aspectos Político-Militares"); Xavier Cordeiro ("Direito e Instituiçôes"); Luis de Almeida Braga ("Lição dos Fatos"). Nem todos tiveram oportunidade de apresentar suas palestras, em função do regresso do Partido Democrático ao poder, ${ }^{28}$ porém os artigos foram publicados. ${ }^{29}$

Pequito Rebelo, embora dissertasse sobre aspectos econômicos, estabeleceu consideraçôes sobre as relações diplomáticas na Península Ibérica. Destacou os pontos negativos do expansionismo e do imperialismo, com exemplos na história nacional, pelo esvaziamento de braços nas terras agricultáveis. Por outro lado, estabeleceu fronteiras entre o nacionalismo e o imperialismo: “(...) ao definir a via de um método positivo quais os limites do nacionalismo que o livram e degeneram nessa forma doentia — o imperialismo." ${ }^{30}$ Para Rebelo, o

\footnotetext{
${ }^{27}$ Cf.: MARTINS, Fernando. O Segundo Integralismo Lusitano e o Salazarismo: origens, decadência e queda. In: SILVA, Giselda Brito; GONÇALVES, Leandro Pereira; PARADA, Maurício B. Alvarez (Orgs.). História da política autoritária: Integralismo - Nacional Sindicalismo - Nazismo - Fascismos. Recife: Editora da UFRPE, 2010, p. 89-113.

28 'A 14 de maio de 1915 as conferências foram interrompidas de forma 'violenta' por 'grupos armados' que aos gritos de 'Viva a República' e 'Viva a Liberdade', assaltaram as instalaçóes da Liga.” FERREIRA, A. Jacinto. Integralismo Lusitano: uma doutrina política de ideias novas. Lisboa: Cultura Monárquica, 1991, p. 54.

${ }^{29}$ Cf.: A QUESTÃO IBÉRICA. Lisboa: Tipografia do Anuário Comercial, 1916. Biblioteca Nacional de Lisboa. Cota: S.C. $99231 \mathrm{~V}$.

${ }^{30}$ REBELLO, José Pequito. Aspectos económicos. In: A QUESTÃO IBÉRICA, op. cit.
} 
imperialismo seria o efeito colateral do individualismo social, incomum na sociedade municipalista lusitana medieval e do século XVI. Por outro lado, dada a natureza étnico-cultural heteróclita da composiçáo espanhola, o imperialismo estava imerso nesse meio social, o que representou risco para Portugal desde sua formação enquanto Estado-Nação. ${ }^{31}$

Nesse ciclo de palestras, Sardinha tinha percepção distinta da sustentada por Rebelo, embora suas conclusôes caminhassem, igualmente, para o temor da anexação. Sardinha manteve contato com o país vizinho desde 1909, por meio dos Jogos Florais de Salamanca, ${ }^{32}$ quando adquiriu reconhecimento e inserção na corte espanhola. Esse contato contribuiu para as divergências com Rebelo. Embora afirmasse: "Castela cobiça-nos desde que é Castela. As suas aspiraçôes nunca satisfeitas são naturais, são consequentes, como centro de gravitação procurando submeter a parte desgarrada do todo", ${ }^{33}$ situou como maior risco de desestabilização de Portugal, aquele dentro de suas fronteiras, ou seja, a ação silenciosa dos estrangeiros do interior. ${ }^{34}$

Não seriam os espanhóis, mas a maçonaria, o principal responsável pelo risco de perda da soberania nacional. Diante dos desequilíbrios políticos e dos espasmos sociais sofridos por Portugal, a invasão de Castela seria realizada pelo convite de Portugal: "A solução intervencionista é lógica, e natural como as coisas que o sáo, quando um importuno nos incomoda e coloca em risco de quebrar o nosso próprio sossego, a nossa própria disciplina." 35

As polêmicas em torno do perigo espanhol às fronteiras portuguesas se arrastaram até o fim da década de 1910. Em "A lição de Bismarck", artigo escrito entre os fins dos anos 1910 e início da década de 1920, mas publicado na coletânea Sob o pendão real, Almeida Braga apresentava sua discordância com Sardinha acerca do panorama político de Portugal e da Espanha: "A república portuguesa tornou-se para a Espanha um apetitoso manjar. A anarquia em que vivemos aguçou-lhe o apetite, acendeu a cobiça com que nos olha." ${ }^{36}$ Apesar de acusar a maçonaria como uma das origens dos distúrbios sofridos por Portugal, Braga apontava a república como risco em potencial para a soberania. Ao depor a monarquia o país tornava-se vulnerável, pois abdicava do pacto histórico selado com a Inglaterra. Além disso, a Espanha, inimiga diplomática tradicional, era vista com desconfiança não apenas por Almeida Braga, mas por grande parte dos membros do Integralismo Lusitano.

Em 1919, degredado de Portugal em vista de novas tentativas de golpe para implemento dos projetos políticos corporativistas, através da Monarquia do Norte e de Monsanto, Sardinha buscou reverter essas sensaçôes negativas partilhadas por seu grupo em relação ao

\footnotetext{
${ }^{31}$ Ibidem, p. 163.

${ }^{32}$ RELVAS, Susana Soares de Silva Rocha. António Sardinha e suas relaçôes culturais com a Espanha: "Pactos de Quinas y Flores de Lis" entre "os semeadores de Nacionalidade”, op. cit., p. 97.

${ }^{33}$ SARDINHA, António. Território e raça. In: A QUESTÃO IBÉRICA, op. cit.

${ }^{34}$ Ibidem, p. 13-14.

${ }^{35}$ Ibidem, p. 13.

${ }^{36}$ BRAGA, Luis de Almeida. A lição de Bismarck. In: BRAGA, Luis de Almeida. Sob o pendão real. Porto: Gama, 1942, p. 320. Biblioteca Nacional de Lisboa. Cota: B.R. 7669.
} 
país vizinho. ${ }^{37}$ Sua escolha pela Espanha como país a recebê-lo no exílio não foi aleatória. Anterior ao julgamento dos levantes, Sardinha tinha residência em Elvas, cidade portuguesa fronteiriça com Badajoz, na Espanha. Desse modo, seu primeiro abrigo seria na Estremadura, haja vista o conhecimento da região, bem como a situação política para se instalar. ${ }^{38}$

Durante o período do degredo, Sardinha alterou sua perspectiva em relação à política diplomática luso-espanhola. Sobre o assunto, o mentor intelectual do Integralismo Lusitano afirmava:

Quando vim para o exílio trazia contra a Espanha todos os preconceitos da minha inteligência e da minha sensibilidade. (...) E ainda aprendera lentamente, mas com juízo seguro, a corrigir bastante das prevençóes do meu patriotismo alarmado ao iniciar em abril de 1915 na Liga Naval as conferências da "Questão Ibérica". 39

Por meio de suas experiências no exílio, Sardinha buscou modificar a concepção de aversão à Espanha, mantidas pelo Integralismo Lusitano. Essa reversão da sensação de desconfiança dos integralistas ao país vizinho se fez com o objetivo de estabelecer o projeto de Aliança Peninsular, que seria exposto em obra de mesmo nome, em 1924. ${ }^{40}$

Aliança Peninsular demarcou a posição de Sardinha de forma nítida, e distinguiu-o de parte considerável dentre os integralistas. Ficou destacado o papel de fundadores de civilizaçóes exercidos tão somente por Portugal e Espanha, tal como o papel central desempenhado pela religiosidade católica para a composição dessa função de “(...) verdadeiramente colonizar, elevando as raças inferiores a uma sociabilidade maior, revestido com os preceitos da fé cristã". ${ }^{41}$ Conforme será visto mais à frente, alguns desses elementos estiveram presentes nas obras de Ganivet.

A circulação de Aliança Peninsular na Espanha encontrou boa acolhida, merecendo tradução e prefácio de Santibañez del Rio, cinco anos após a morte de Sardinha. É percebida a alteração das imagens construídas por Sardinha sobre o país vizinho, de ameaça

\footnotetext{
${ }^{37}$ Ana Isabel Devignes destaca esse período como o deflagrador, através do degredo, da apologia sustentada por Sardinha, a respeito da "Aliança Peninsular". Cf.: DEVIGNES, Ana Isabel Sardinha. Hispanismo e relaçóes luso-brasileiras: a última cruzada contrarrevolucionária de António Sardinha. Estudos IberoAmericanos, Porto Alegre, v. 42, n. 1, p. 75-104, jan./abr. 2016, p. 77.

${ }^{38}$ RELVAS, Susana Soares de Silva Rocha. António Sardinha e suas relaçóes culturais com a Espanha: "Pactos de Quinas y Flores de Lis" entre "os semeadores de Nacionalidade", op. cit., p. 99.

${ }^{39}$ SARDINHA, António. A descoberta da Espanha. A Monarquia: Diario Integralista da Tarde, Lisboa, 5 set. 1919. n. 541, p. 1. Universidade Católica Portuguesa, Biblioteca João Paulo II, Espólio António Sardinha. Cota: 5051.

${ }^{40}$ SARDINHA, António. La Alianza Peninsular. Prólogo de Ramiro de Maeztu. Tradução para o espanhol de Marques de Quintanar, conde de Santibañez Del Rio. Madri: Junta de Propaganda Patriótica y Ciudadana, impresso por Saez Hermanos, 1930.

41 "Sólo los españoles y los portugueses supieron verdaderamente colonizar, elevando a las razas inferiores a uma sociabilidad mayor, esmaltado con los preceptos de la fe Cristiana" (tradução livre). Ibidem, p. 71.
} 
fusionista, migrando para reduto de segurança por meio de alianças e consolidação de vínculos peninsulares, diante da imagem da "Madre Hispania". O integralista compreendia a aliança hispânica como uma obra de manutenção do tradicionalismo, caro ao seu conjunto teórico, pela renovação política e espiritual do Ocidente. No seu entender, tal renovação seria tarefa incumbida aos povos hispânicos e de tradição hispânica. ${ }^{42}$

Essa construção étnica e territorial, consolidada na integração da Península Ibérica por meio de alianças políticas e diplomáticas, inseria Portugal e Espanha ${ }^{43}$ na oposição aos demais países, com destaque aos anglo-saxões, para os quais, segundo o integralista, os "fundamentos assentaram no extermínio sistemático das populaçóes indígenas". ${ }^{4}$ $\mathrm{O}$ hispanismo de Sardinha era norteado pela "ideia de solidariedade social e espiritual necessárias, como pão para boca ao prestígio e à vitalidade externa de ambas as pátrias”. ${ }^{45}$ Nesses projetos não se propunha o surgimento de uma nova "raça", mas a coesão do plano de civilização, tal como estabelecido por Portugal e pela Espanha, conforme a leitura histórica feita por António Sardinha. Essa concepção forneceu suporte para alimentar projetos hispano-americanistas.

Em contato com os autores do "Desastre" espanhol, Sardinha passou a sustentar, como consequência dos diálogos estabelecidos, a importância de se restabelecer relaçôes com as antigas colônias, que alternavam em seus textos ora a posição de irmãs, ora a de filhas de Portugal e da Espanha. Assim, Sardinha investia na imagem de um nacionalismo transnacional, que excedia as fronteiras dos países envolvidos, justamente por não contemplar ambiçóes anexionistas. Ao celebrar a Festa da Raça de 1921, ${ }^{46}$ Sardinha apresentou as formas como se desdobrariam a reabilitação das relaçôes entre o mundo ibérico e os países latino-americanos, de modo que:

(...) o dia de hoje exige-nos sereníssima meditação sobre que o destino futuro nos reserva, se olhando para o lado de cá do Atlântico, soubemos compreender que, antes de tudo, as duas

42 DEVIGNES, Ana Isabel Sardinha. Hispanismo e relaçôes luso-brasileiras: a última cruzada contrarrevolucionária de António Sardinha, op. cit., p. 77.

43 SARDINHA, António. Madre-Hispania. Nação Portuguesa: Revista de Cultura Nacionalista, Lisboa, 3 série, p. 117, 1924. Real Gabinete Português da Leitura: CDU 050, RGPL 4UU6. Registro: 207116.

${ }^{44}$ Ibidem, p. 104.

${ }^{45}$ SARDINHA, António. A descoberta da Espanha (1919). In: SARDINHA, António. À lareira de Castela. Lisboa: Gama, 1943, p. 8.

${ }^{46}$ Essas festividades e comemoraçôes foram realizadas no intuito de celebrar o casamento dos filhos de Felipe V com os príncipes lusitanos. (SARDINHA, António. Madre-Hispania, op. cit., p. 97. Affonso Lopes Vieira afirma que o evento contribuiu para a consolidação do projeto de formar o bloco Luso-Hispano-Americano, ou Quinto Império - conforme denominado pelo autor — , constituído por países da Península Ibérica e da Hispano América, incluindo o Brasil (VIEIRA, Affonso Lopes. Palavras em louvor da "Festa da raça". Nação Portuguesa: Revista de Cultura Nacionalista, Lisboa, 2 série, 2 v., p. 147, 1922-1923. Real Gabinete Português da Leitura: CDU 050, RGPL 4UU5. Registro: 104444). Complementar à definição de Lopes Vieira há, sobre a comemoração: “(...) aclamaciones a la joven América, entusiasmos por la Madre España y demás manifestaciones de sentimentos familiares que, por su forma yo me atreveria a calificar de crusis." (BALLESTEROS, D. Antonio. La fiesta de la raza. Nação Portuguesa: Revista de Cultura Nacionalista, Lisboa, 2 série, 2 v., p. 149, 1922-1923. Real Gabinete Português da Leitura: CDU 050, RGPL 4UU5. Registro: 104444). 
pátrias peninsulares precisam entender-se para irem depois à reconquista espiritual dessas vinte e tantas nacionalidades, que ambas souberam criar e que tão desejosas se mostram de conhecer de perto a casa paterna. ${ }^{47}$

Entre o início de anos 1910 e o fim da mesma década, portanto, percebe-se a alteração das concepçóes políticas, influenciadas, em parte, pelas experiências que incidiram sobre a visão de mundo que norteava intelectual e ideologicamente António Sardinha. Em função dessas experiências se colocarem no campo subjetivo, para servir de base de transformação da teoria integralista, que se propunha objetiva, o mentor integralista não deteve a hegemonia interna e sofreu oposição, com relação ao intuito de alterar o sentimento de alerta e desconfiança de seus colegas de grupo sobre a Espanha.

Isso se explica, em parte, pelos mecanismos de elaboração de interpretaçóes do mundo, o que acarreta a inspiração para construção de projetos ou mesmo adesão aos já existentes. Angela de Castro Gomes e Patricia Hansen entendem que "os intelectuais têm um processo de formação e aprendizado sempre atuando em conexão com outros atores sociais e organizações, intelectuais ou não, e tendo projetos no entrelaçamento entre a cultura e o político" ${ }^{48}$

$\mathrm{Na}$ mesma via de Gomes e Hansen, Pierre Ansart apresenta a dependência existente entre a produção dos bens simbólicos e sua inserção na vida coletiva, condiçóes particulares de emissão e recepção de determinados códigos e agentes, eles mesmos, inseridos em uma posição determinada. ${ }^{49}$ Reúne-se, a partir desses componentes, elementos para a composição de uma ideologia, uma corrente política significativa para um grupo restrito, que se propóe irradiar para além de seus limites, como projeto coletivo, e que contemple a todos (uma região, uma nação ou etnia, um país).

No degredo Sardinha tomou contato com outros espaços de sociabilidade e círculos intelectuais, o que alterou suas concepçóes, deformando visôes de mundo anteriores, conforme já mencionado. Tais aspectos foram imperativos para a consolidação do projeto hispanista pelo mentor do Integralismo Lusitano. Paulo Ferreira aponta a possibilidade de Sardinha ter sido o primeiro autor português a utilizar a noção de hispanismo com bases bastante próximas ao percebido entre os católicos tradicionalistas da Espanha, ${ }^{50}$ porém sem ignorar matrizes lusitanas do século XIX, ao estabelecer debate sobre o "iberismo" de Antero de Quental e fazer referências a Oliveira Martins.

Nesse propósito, Angel Ganivet foi importante elemento de inspiração e de difusão do projeto hispanista, irradiando suas concepçôes para autores conservadores e progressistas.

\footnotetext{
${ }^{47}$ SARDINHA, António. A descoberta da Espanha (1919), op. cit., p. 76.

${ }^{48}$ GOMES, Angela de Castro; HANSEN Patricia Santos. Apresentação: intelectuais, mediação cultural e projetos políticos: uma introdução para delimitação do objeto e estudo. In: GOMES, Angela de Castro; HANSEN, Patricia Santos (Orgs.). Intelectuais e mediaçôes: práticas culturais e açôes políticas. Rio de Janeiro: Civilização Brasileira, 2016, p. 12.

${ }^{49}$ ANSART, Pierre. Ideologie, conflits e pouvoir. Paris: Presses Universitaires de France, 1977, p. 15.

${ }^{50}$ FERREIRA, Paulo Bruno Rodrigues. Iberismo, hispanismo e seus contrários: Portugal e Espanha (19081931), op. cit., p. 104.
} 
Sardinha salienta sua importância ao elogiá-lo e à sua obra, em relação à importância para o reforço da nacionalidade espanhola, pois "Foi Angel Ganivet um dos mais fortes e mais originais pensadores de Espanha nos últimos trinta anos". ${ }^{51}$

Porém, na mesma obra, Sardinha deixa claro que não é o fato de partilharem projetos congêneres que o dotaria de simpatia generalizada e incondicional. Por um lado, Espanha e Portugal buscavam redefinir suas identidades nacionais em momento crítico, por outro os intelectuais desses países buscavam definir seus interlocutores. Se Unamuno estabeleceu contato com Ganivet, pela troca de correspondências, por dois anos, ${ }^{52}$ e o mesmo Ganivet influenciou intelectuais portugueses e espanhóis, isso não significou a formação de coesão entre os leitores ou àqueles que partilharam da mesma experiência do "Desastre" espanhol, conforme pode ser demonstrado por António Sardinha, ao referir-se a Unamuno e Ortega y Gasset com palavras pouco lisonjeiras:

São os sofistas de ínfima espécie - genuínos palhaços da Inteligência, como Unamuno e Ortega y Gasset, quem rouba à nação irmã a flama épica em que ela estremece até à medula dos ossos. É um bando de invertebrados e desnacionalizados que preparam para a sua terra o abismo moral e social em que a nossa abala perdida... ${ }^{53}$

Portanto, Ganivet não se fez importante apenas entre os espanhóis. Por outro lado, foi fundamental para a geração do "Desastre", tomada pelo pessimismo e pela desilusão da virada do século XIX para o XX, mas por meio do debate, Ganivet contribuiu para a geração de projetos políticos de reorganização diplomática espanhola, pelo esforço voltado aos países latino-americanos. Mesmo alimentando oposição em pontos importantes de seu pensamento, Miguel de Unamuno reconhecia ser admirador de Ganivet. ${ }^{54}$

\section{Ganivet e Unamuno: hispanismo no "Desastre"}

O reconhecimento dos intelectuais não se faz espontaneamente. As condiçóes exigidas, conforme Dosse destacou, são a participação no domínio da política, e, por tomar parte no combate público, emigrando de campo intelectual e engajando-se. ${ }^{55} \mathrm{Na}$ mesma via, Lewis Coser apontou para a exigência da formação do "auditório", ou seja, um círculo de pessoas que atribuem o reconhecimento como intelectual, assim como seus pares. ${ }^{56}$

\footnotetext{
${ }^{51}$ SARDINHA, António. A agonia de Agatáo Tinoco. In: SARDINHA, António. À lareira de Castela. op. cit., p. 25.

${ }^{52}$ UNAMUNO, Miguel de; GANIVET, Angel. El porvenir de España, op. cit., p. 14.

53 SARDINHA, António. Paixão de Espanha. In: SARDINHA, António. À lareira de Castela, op. cit., p. 87.

${ }^{54}$ FERREIRA, Paulo Bruno Rodrigues. Iberismo, hispanismo e seus contrários: Portugal e Espanha (19081931), op. cit., p. 122.

${ }^{55}$ DOSSE, François. La marcha de las ideas: historia de los intelectuales, historia intelectual, op. cit., p. 66-67. ${ }^{56}$ COSER, Lewis A. Hombres de ideas: El punto de vista de un sociológo. México D.F.: Fondo de Cultura Económica, 1980, p. 19.
} 
Se, no contexto português, a emergência dos colegas da Universidade de Coimbra como organização do Integralismo Lusitano aconteceu após a proclamação da república, exílio de alguns e frustração de outros, na Espanha, a emergência da "Geração de 1898" ocorreu por intermédio do "Desastre", quando o país foi derrotado pelos Estados Unidos em sucessivas disputas territoriais, resultando na perda de Cuba, de Porto Rico e das Filipinas. Tais derrotas praticamente decretaram o fim do império espanhol além-mar, e sinalizaram para o posicionamento do país na corrida imperialista, colocando-se à periferia da disputa por novas colônias.

As crises políticas e diplomáticas referentes aos países ibéricos não eram fenômenos inéditos desde o começo de sua história contemporânea. No entanto, os acontecimentos inaugurados no final do século XIX foram responsáveis pelo pessimismo que caracterizou a geração de intelectuais portugueses e espanhóis. ${ }^{57}$ Maria Helena Capelato define a chamada "Geração de 1898" como a manifestação da "angústia pelo estado de decadência a que estava submetida a Espanha" ${ }^{58}$ No esforço de buscar superar tal pessimismo, engajaram-se por estabelecer caminhos para a inserção à modernidade, sem desgastar ou suplantar as particularidades espanholas. Angel Ganivet demonstrava sua preocupação em relação ao processo de transição à modernidade: "Queremos ter exércitos iguais aos do Continente, e nosso caráter pede, exige, um exército peninsular." ${ }^{59}$ E completa: "Como há continentes, penínsulas e ilhas, também existem espíritos continentais, peninsulares e insulares."60

Como forma de se reinserir no novo contexto, as relaçôes diplomáticas institucionais espanholas, em final dos anos 1890 e início do século XX caminharam para a aproximação com a América Latina de língua castelhana, com a finalidade de articular relaçóes fraternas, mas, igualmente, por estreitar acordos comerciais. ${ }^{61}$ Tais relaçôes foram intercambiáveis entre a política institucional e os intelectuais. Miguel de Unamuno, segundo Stephen Roberts, migrou entre os anos de 1897 e 1900 da ênfase à modernização e inserção na europeização para o progressivo destaque das características que discerniam a Espanha dos países vizinhos. ${ }^{62}$ Ganivet, por sua vez, fortalecia os projetos de alianças entre espanhóis, portugueses, brasileiros e os países da América de fala castelhana. Tratava-se, portanto, do processo de recuperação das identidades de Portugal e da Espanha, por meio do projeto de alianças entre esses países e seus "herdeiros", conforme entendiam com maior vigor Ganivet e Sardinha.

\footnotetext{
${ }^{57}$ FERREIRA, Paulo Bruno Rodrigues. Iberismo, hispanismo e seus contrários: Portugal e Espanha (19081931), op. cit., p. 59.

${ }^{58}$ CAPELATO, Maria Helena Rolim. A data símbolo de 1898: o impacto da independência de Cuba na Espanha e na Hispanoamérica, op. cit., p. 37.

59 "Nosotros queremos tener ejércitos iguales a los del Continente y nuestro carácter pide, exige, un ejército peninsular." GANIVET, Angel. Idearium español. Granada: Vda. E Hijos de Paulino V. Sabatel, 1897, p. 52 (tradução livre).

${ }^{60}$ "Como hay continentes, penínsulas e islas, así hay también espiritus continentales, peninsulares e insulares." Ibidem, p. 31 (tradução livre).

${ }^{61}$ GOUVEIA, Regiane Cristina. A “Geração de 1898”, o "Desastre” e a retomada das relações entre Espanha e as repúblicas hispano-americanas, op. cit.

${ }^{62}$ ROBERTS, Stephen G. H. "Hispanidad": el desarrollo de una polémica noción en la obra de Miguel de Unamuno. Cuad. Cát. M. de Unamuno, n. 39, p. 61-80, 2004. p. 63.
} 
Embora Unamuno e Ganivet se aproximassem em seus projetos políticos e suas alternativas para a Espanha transitar pelo caminho tênue entre a modernidade e a identidade, ou espírito nacional, apresentaram demarcaçóes e limites em suas propostas, delimitando a originalidade dos respectivos pensamentos. Uma definição de autoria de Ganivet, que influenciou autores espanhóis e portugueses presentes no mesmo recorte temporal, é a que recai sobre espírito, usado em termos similares tanto por Unamuno quanto por António Sardinha, ainda que este último, conforme visto, nutrisse rejeição a Miguel de Unamuno.

Em Idearium español, Ganivet afirma que a religiosidade é algo importante para a definição da identidade de um país, no entanto, não é o determinante fundamental. Para ele, a religião pode até ser alterada, todavia, restam características de cunho invariável, criadas a partir do território. Assim, os povos adquirem as características inerentes aos seus territórios. ${ }^{63}$ Entendia serem componentes de uma grande família “espiritual” Aragão, Catalunha, Castela, portanto, Espanha e Portugal, asseverando que a guerra viria tão somente separá-los historicamente. A proposta não implicava dano à independência ou à autonomia. Com a preservação da unidade pela legalidade política estabelecida, não haveria agressão. ${ }^{64}$

Deste modo, a proposta que reveste a definição de "espírito" de Ganivet é muito próxima à de "raça", utilizada por Sardinha para designar o povo ou a civilização lusitana. Assim era apresentada explicação do uso em Nação Portuguesa, revista do Integralismo Lusitano: "Mais duma vez temos dito, e nunca é demais repeti-lo, que 'raça' aqui não se reveste dum estreito sentido étnico. Remontando as origens da palavra, deve exprimir-se antes - e exprime-o seguramente —, um sentido espiritual de 'raiz." 65 "Raça" estaria ligada à tradição. A partir de costumes e normas dispostas, historicamente se identificaria os portugueses como semelhantes entre si, ligando-os a um grupo que se concentra na nação, ou seja, Portugal. Porém, em alguns momentos, o conceito utilizado por Sardinha dotava-se de forte teor biológico. ${ }^{66}$

Se era pretendida a fraternidade pela partilha do espírito comum, herdado pelos países ibéricos, aos demais territórios, por meio da colonização, a partilha de valores e os laços de amizade não se ofereciam de forma universal. Ganivet entendia que a confraternização seria ligada pelo verdadeiro cristianismo, alcançado pela "ação permanente de uma raça superior, (...) como ocorreu com os povos descobertos e subjugados pela Espanha”. ${ }^{67}$

\footnotetext{
${ }^{63}$ GANIVET, Angel. Idearium español, op. cit., p. 31.

${ }^{64}$ Ibidem, p. 42.

${ }^{65}$ REDACÇÃO. A festa da raça. Nação Portuguesa: Revista de Cultura Nacionalista. Lisboa: 3 série. 1924, p.

${ }^{67}$ Real Gabinete Português da Leitura: CDU 050, RGPL 4UU6. Registro: 207116.

${ }^{66}$ Sardinha, em Ao ritmo da ampulheta, livro de publicação póstuma, datada de 1925, faz referência à contaminação através do sangue negro e do individualismo, com o advento das navegaçóes à Índia. Na cobiça pelo ouro fácil, Sardinha expunha: "O trabalho afrouxa e quase se extingue nos vilares da metrópole, onde só uma enxurrada de escravos avulta. O sangue negro contamina-nos. Contamina-nos o individualismo solto da Renascença. Principia a decadência - Portugal desnacionaliza-se." SARDINHA, António. Ao ritmo da ampulheta. 2. ed. Lisboa: Qp, 1978, p. 145 (grifo nosso).

67 "El verdadero cristianismo, no como aspiración filantrópica en favor de razas inferiores, sino como conscientemente profesada, es impropio de pueblos primitivos y solo arraiga en éstos cuando le acompaña la acción permanente
} 
Nesses termos, o autor buscou rivalizar com os assédios imperialistas e concorrer com o discurso de que os países aderentes ao protestantismo, ou por ele colonizados, tiveram melhor sorte em termos de desenvolvimento "cultural, de maior prosperidade, maior influência política em relação aos que permaneceram fiéis ao catolicismo" ${ }^{68} \mathrm{Se}$, por um lado, para Ganivet o catolicismo era inerente ao espírito ibérico, o mesmo não foi determinante no desenvolvimento econômico, social ou político negativo, porém alternativo ao que foi presenciado pelas outras potências europeias, retórica similar à lançada por Sardinha quando dizia serem Portugal e Espanha "semeadores de naçóes", conforme visto anteriormente. Nesta esteira, Miguel de Unamuno também buscou formar resistência contra o imperialismo estrangeiro, porém, com maior destaque, segundo Roberts, à investida contra a influência francesa na hispano-América. ${ }^{69}$

Todavia, Unamuno buscou separar de forma clara os limites entre a religiosidade e a política, ao contrário de Ganivet, que entendia estar no cristianismo um dos eixos de definição da unidade ibérica e do espírito hispânico. Unamuno, por sua vez afirmava o cristianismo como apolítico, portanto, inacessível aos limites institucionais do Estado, seja para a defesa da democracia, seja para a legitimação da centralização política. ${ }^{70}$

A trajetória de Unamuno é tomada por rupturas de itinerário, marcante pela transferência da ênfase à inserção na modernização europeia, para a valorização da identidade ibérica, em detrimento dos países vizinhos. La agonia del cristianismo tem sua primeira edição lançada em 1924. Portanto, em meados da segunda década do século XX, o autor estava engajado em estabelecer relaçáo com os autores sul-americanos, coerente com a proposta de firmar vínculos identitários ibéricos. Ainda assim, defendia a necessidade de manter distância entre a religião e o Estado. Logo, percebem-se as demarcaçôes específicas no pensamento de cada autor, em vista das propostas coerentes às trajetórias estabelecidas.

Os contatos e as rivalidades também são explicados pelo itinerário de cada intelectual, e de suas respectivas formaçôes e inserçôes nas redes de sociabilidade. Assim, destaca-se a rejeição incondicional de Sardinha a Unamuno, embora ambos partilhassem a admiração pela obra de Angel Ganivet. Por outro lado, tal valorização não significou a incorporação completa da teoria de hispanismo de Ganivet à de Sardinha e Unamuno, pelo contrário, o que se percebeu foi intenso debate entre os autores.

\footnotetext{
de una raza superior, es decir cuando ese pueblo primitivo se confunde por la vía común ó por el cruce con un pueblo civilizado que le domina y le educa, como ocurrió en los pueblos descubiertos y subyugados por España." GANIVET, Angel. Idearium español, op. cit., p. 24.

${ }^{68}$ Ibidem, p. 26.

${ }^{69}$ ROBERTS, Stephen G. H. "Hispanidad": el desarrollo de una polémica noción en la obra de Miguel de Unamuno, op. cit., p. 70.

${ }^{70}$ UNAMUNO, Miguel de. La agonía del cristianismo. Buenos Aires: Editorial Losada, 1938, p. 81.
} 


\section{Considerações finais}

Percebe-se a divergência com os projetos de Ganivet, ainda que ambos concordassem com a necessidade de a Espanha recuperar seu protagonismo anterior, e isso seria adquirido pela revitalização do diálogo com os países de língua espanhola/castelhana. Tal distinção entre os projetos, ao menos quanto à associaçáo do cristianismo e do Estado, torna-se saliente quando Unamuno responde a Ganivet: "Sei que a muitos parecerá uma atrocidade o que vou dizer, quase uma heresia, mas entendo e afirmo que essa fusão que se estabelece entre o patriotismo e a religião é danosa para ambos." 71

$\mathrm{O}$ acordo era percebido no interesse mantido em associar os dois países ibéricos, no intuito de estabelecer resistência ao assédio do imperialismo político e cultural anglo-saxão e francófono. Unamuno buscava o maior diálogo entre os vizinhos, entre outros aspectos, pela proximidade que as línguas mantêm entre o português e o espanhol, julgando ser absurdo que se mantenham separados em termos "espirituais". Afirmava ser mais fácil encontrar em Madri um livro inglês, alemão ou italiano que um português, e contava uma anedota em que em uma faculdade de medicina portuguesa "se servem da obra de nosso Ramón y Cajal, mas... em francês". ${ }^{72} \mathrm{Na}$ mesma via, Ganivet sustentava a necessidade de fomentar reação frente às correntes e doutrinas imperialistas, tais como a Doutrina Monroe:

Será me dito que a África está repartida como pão bento; mas esteve repartido o mundo ou pouco menos entre Espanha e Portugal, e veja você onde se chegou. Em nossos dias temos visto aparecer doutrinas como a de Monroe e a de proteção do interesse, da ocupação efetiva e do arrendamento. ${ }^{73}$

É nítida, salvaguardadas as devidas especificidades entre os autores, a influência exercida por Ganivet em pensadores que excedem as fronteiras espanholas. Seu conceito de "espírito" que canalizava os aspectos definidores de um povo era dinâmico, de modo a contemplar dentro dessa hispanidade naçôes que falavam o espanhol, mas igualmente Portugal e Brasil. ${ }^{74}$ Diante da prerrogativa, Sardinha dialogou com Ganivet, a partir de um conto deste último, "A agonia de Agatão Tinoco".

Em certa altura Idearium español narra os últimos instantes de Tinoco, que gostaria de conversar com algum compatriota, por estar já moribundo no Congo. De fala espanhola, os enfermeiros localizaram Ganivet, porém, em conversa, Agatão apresenta-se como centro-

\footnotetext{
71 "Sé que a muchos parecerá lo que voy á decir una atrocidad, casi una herejía, pero creo y afirmo que esa fusión que se establece entre el patriotismo y la religión, daña a uno y a otra." UNAMUNO, Miguel de; GANIVET, Angel. El porvenir de España, op. cit., p. 131 (tradução livre).

${ }^{72}$ UNAMUNO, Miguel de. Por tierras de Portugaly de España. Madri: Biblioteca Renacimiento, 1911, p. 15. 73 "Se me dirá el África esta ya repartida como pan benedito; pero también estuvo repartido el mundo ó poco menos entre España y Portugal, y ya ve usted á onde llegado. En nuestros días hemos visto aparecer doctrinas flamantes como la de Monroe y la de protección de interés, la de ocupación efectiva y la del arrendamiento." UNAMUNO, Miguel de; GANIVET, Angel. El porvenir de España, op. cit., p. 86-87 (tradução livre).

${ }^{74}$ FERREIRA, Paulo Bruno Rodrigues. Iberismo, hispanismo e seus contrários: Portugal e Espanha (19081931), op. cit., p. 66.
} 
-americano e de família portuguesa. Em meio à apresentação, Ganivet interrompe-o ao afirmá-lo como espanhol três vezes, em vista da herança que seu país tinha da Espanha, e pelos laços que Portugal mantinha como nação integrante da Península Ibérica e, portanto, da Hispania. ${ }^{75}$ Nestes termos, Sardinha elogiava o escritor espanhol, em artigo de mesmo nome que o personagem de Ganivet, ao perceber no "Idearium español - espécie interessante de breviário nacionalista, muita página, cuja meditação refletida se impóe como um dever a nós outros portugueses" ${ }^{76}$ E concordava, mais uma vez, sobre a origem da decadência peninsular, encontrada na "falta de fraternidade de nosso espírito". ${ }^{77}$ Porém, em relação a Unamuno, Sardinha não reservava as mesmas palavras afetuosas, atacando-o como "bufarinheiro", e se por alguma vez conseguiu reverberar patriotismo, foi simplesmente por ser eco de Ganivet. ${ }^{78}$

Deste modo, é percebida a heterogeneidade existente entre os limites e as relaçóes de afiliaçáo, contato e tensão existentes entre os projetos sustentados, por mais similares que pudessem parecer. Ressalta-se a complexidade em definir as alianças e redes que permeiam o campo intelectual, em função das especificidades dos autores, em vista de suas trajetórias de pensamento e mesmo geracionais, que permitem transitar com maior fluidez entre grupos diferentes, sem que isso incorra em incoerência, incompatibilidade ou interrupção de intercâmbio de ideias. Deste modo, destaca-se a riqueza apresentada pela associação da história política com a intelectual, no intuito de expor e analisar os projetos políticos consolidados pelos pensadores engajados em fornecer alternativas de regimes e modelos de exercício de poder para seus respectivos países.

\section{Fontes primárias}

A QUESTÃO IBÉRICA. Lisboa: Tipografia do Anuário Comercial, 1916. Biblioteca Nacional de Lisboa. Cota: S.C. $99231 \mathrm{~V}$.

BALleSterOS, D. Antonio. La fiesta de la raza. Nação Portuguesa: Revista de Cultura Nacionalista, Lisboa, 2 série, 2 v., 1922-1923. Real Gabinete Português da Leitura: CDU 050, RGPL 4UU5. Registro: 104444.

BRAGA, Luis de Almeida. A lição de Bismarck. BRAGA, Luis de Almeida. Sob o pendão real. Porto: Gama, 1942, p. 320. Biblioteca Nacional de Lisboa. Cota: B.R. 7669.

GANIVET, Angel. Idearium español. Granada: Vda. E Hijos de Paulino V. Sabatel, 1897.

. El porvenir de España. Madri: Renacimiento Sociedad Anonima Editorial, 1912.

MAURRAS, Charles. Quand les Française ne s'aimaient pas: chronique d'une Renaissance 1895-1905. 2. ed. Paris: Nouvelle Librarie Nationalle, 1916.

SARDINHA, António. A descoberta da Espanha. A Monarquia: Diario Integralista da Tarde, Lisboa, 5 set. 1919 . n. 541.

. À lareira de Castela. Lisboa: Gama, 1943.

\footnotetext{
${ }^{75}$ GANIVET, Angel. Idearium español, op. cit., p.110.

${ }^{76}$ SARDINHA, António. Agatão Tinoco (1919), op. cit., p. 25.

${ }^{77}$ Ibidem, p. 30.

${ }^{78}$ Ibidem, p. 25.
} 
. Ao ritmo da ampulheta. 2 ed. Lisboa: Qp, 1978.

- La Alianza Peninsular. Prólogo de Ramiro de Maeztu. Tradução para o espanhol de Marques de Quintanar, conde de Santibañez Del Rio. Madri: Junta de Propaganda Patriótica y Ciudadana, impresso por Saez Hermanos, 1930.

. Madre-Hispania. Nação Portuguesa: Revista de Cultura Nacionalista, Lisboa, 3 série, 1924.

UNAMUNO, Miguel de. La agonía del cristianismo. Buenos Aires: Editorial Losada, 1938.

. Por tierras de Portugal y de España. Madri: Biblioteca Renacimiento, 1911.

UNAMUNO, Miguel de; GANIVET, Angel. El porvenir de España. Madri: Renacimiento Sociedad Anonima Editorial, 1912.

VIEIRA, Affonso Lopes. Palavras em louvor da "festa da raça". Nação Portuguesa: Revista de Cultura Nacionalista, Lisboa, 2 série, 2 v., 1922-1923, p. 147. Real Gabinete Português da Leitura: CDU 050, RGPL 4UU5. Registro: 104444.

\section{Referências bibliográficas}

ANSART, Pierre. Ideologie, conflits e pouvoir. Paris: Presses Universitaires de France, 1977. ASCENSÃO, Leão Ramos. O Integralismo Lusitano. Lisboa: Gama, 1943.

CAPELATO, Maria Helena Rolim. A data símbolo de 1898: o impacto da independência de Cuba na Espanha e na Hispanoamérica. História, São Paulo, v. 22, n. 2, p. 35-58, 2003.

COSER, Lewis A. Hombres de ideas: el punto de vista de un sociológo. Ciudad de México: Fondo de Cultura Económica, 1980.

DEVIGNES, Ana Isabel Sardinha. Hispanismo e relaçóes luso-brasileiras: a última cruzada contrarrevolucionária de António Sardinha. Estudos Ibero-Americanos, Porto Alegre, v. 42, n. 1, p. 75-104, jan./abr. 2016.

DOSSE, François. La marcha de las ideas: historia de los intelectuales, historia intelectual. València: Universitat de València, 2007.

FERREIRA, A. Jacinto. Integralismo lusitano: uma doutrina política de ideias novas. Lisboa: Cultura Monárquica, 1991, p. 54.

FERREIRA, Paulo Bruno Rodrigues. Iberismo, hispanismo e seus contrários: Portugal e Espanha (1908-1931). Tese (Doutorado em História) — Universidade de Lisboa, Lisboa, 2016.

GOUVEIA, Regiane Cristina. A “Geração de 1898”, o “Desastre” e a retomada das relaçôes entre Espanha e as repúblicas hispano-americanas. Simpósio Nacional de História ANPUH, jul. 2011, São Paulo. Anais do XXVI Simpósio Nacional de História - ANPUH, São Paulo, julho de 2011.

GOMES, Angela de Castro; HANSEN Patricia Santos (Orgs.). Intelectuais e mediaçóes: práticas culturais e ações políticas. Rio de Janeiro: Civilização Brasileira, 2016.

MARTINS, Fernando. O Segundo Integralismo Lusitano e o Salazarismo: origens, decadência 
e queda. In: SILVA, Giselda Brito; GONÇALVES, Leandro Pereira; PARADA, Maurício B. Alvarez (Org.). História da politica autoritária: Integralismo - Nacional Sindicalismo Nazismo - Fascismos. Recife: Editora da UFRPE, 2010.

PINTO, António Costa. Os Camisas Azuis: ideologia, elites e movimentos fascistas em Portugal - 1914-1945. Lisboa: Editorial Estampa, 1994.

RAPOSO, Hipólito. Dois nacionalismos: L'Action Française e o Integralismo Lusitano. Lisboa: Livraria Ferrin, 1929.

RELVAS, Susana Soares de Silva Rocha. António Sardinha e suas relaçóes culturais com a Espanha: "Pactos de Quinas y Flores de Lis" entre "os semeadores de nacionalidade". Dissertação (Mestrado em Literatura Comparada Portuguesa e Espanhola) — Faculdade de Ciências Sociais e Humanas da Universidade Nova de Lisboa, Lisboa, 1998, p. 99. Biblioteca Nacional de Lisboa. Cota: L.62184V.

REMOND, René (Org.). Por uma história politica. Rio de Janeiro: Editora UFRJ/Fundação Getulio Vargas, 1997.

ROBERTS, Stephen G. H. "Hispanidad": el desarrollo de una polémica noción en la obra de Miguel de Unamuno. Cuad. Cát. M. de Unamuno, n. 39, p. 61-80, 2004.

SILVA, Helenice Rodrigues da. Fragmentos da história intelectual: entre questionamentos e perspectivas. Campinas, SP: Papirus, 2002.

SIRINELLI, Jean-François. Intellectuels et passions françaises: manifestes et petitions au XX siècle. Paris: Librairie Arthème Fayard, 1990.

VRBATA, Ales Tenório Luna. La philosophie maurrasianne et les modalités du Fascisme au Portugal. Kias Paper, p. 21-57, 2006. (Cabinet of Ibero-american Studies: Faculty of Humanities: University Hradec Králové).

WINOCK, Michel. O século dos intelectuais. Rio de Janeiro: Bertrand Brasil, 2000.

\section{Como citar:}

CAZETTA, Felipe. História intelectual e projetos políticos nas propostas de hispanismo de António Sardinha, Angel Ganivet e Miguel de Unamuno. Topoi. Revista de História, Rio de Janeiro, v. 19, n. 38, p. 169-189, mai./ago. 2018. Disponível em: <www.revistatopoi.org>. 